\title{
Systemic integrated method for assessing factors affecting construction timelines
}

\author{
Azary Lapidus ${ }^{1 *}$, and Ivan Abramov ${ }^{1}$ \\ ${ }^{1}$ Moscow State University of Civil Engineering, Yaroslavskoye Shosse, 26, Moscow, Russia
}

\begin{abstract}
To streamline construction planning, one needs to assess and perform trial modeling of organizational and process-related factors impacting the final planned performance indicators. A proper calendar plan, one that would take due account of said factors, has a substantial impact on the efficiency and, sometimes, even the feasibility of a construction project as a whole. Therefore, the purpose of this paper's research is to develop a method for determining optimum technical and economic parameters. A method should be considered legitimate which, given the labour intensity of the jobs assigned to a crew and the list of such jobs, makes it possible to determine the time said jobs will take to perform depending on the variation of the following factors: crew/unit numbers, job synchronization degree, job performance sequence, number of shifts and unit productivity. The authors have studied the algorithm and the method for the trial modeling of organizational and process-related factors when developing a calendar plan in order to identify qualitative time-specific and feasibility parameters. The paper reviews the example of how the optimum performance timelines for each crew can be determined.
\end{abstract}

\section{Introduction}

The process of construction and installation work is the key part of implementing a construction project as a whole. In terms of time and space it is the erection technology used on site that determines exactly how the construction and installation work has to be organized. Just as a construction firm can have capacity reserves or capacity deficits when planning and developing averaged conditions for performing work at various types of facilities, a construction crew can have spare reserves due to the fact that its headcount and skills may fall short of being optimum with respect to the work performed in a given work zone. Thus, according to the Russian urban planning standards currently in force as well as applicable SNiP Standards [1], construction timelines are determined at the initial stage of design [2] in the Construction Master Plan section and are specified in years and decades [3]. Upon identification of the headcount and skills of crews based on labor intensity, process

* Corresponding author: aljurgaitis@gmail.com 
flow diagrams and uniform standards and quotations (USQ), an adjusted calendar plan is drawn up $[3,4]$.

Let us consider the existing method. This method widely used in the former Soviet republics to design the crew composition has a number of drawbacks resulting in a difference between actual and planned performance indicators. Such drawbacks include:

- Parameters of jobs (for example, the degree to which jobs done by individual crew units can be synchronized) are not taken into account when the crew numbers are calculated;

- Individual units are supposed to work an average time;

- No trial modeling is performed when the sequence of jobs assigned to the crew is designed;

- Hidden idle time of crew units for process and other reasons is not taken into account when a crew is composed;

- the impact of integrated teams on performance and reliability is not studied.

In connection with this, the method for determining internal crew plans and the composition of integrate crews should be based on the following important requirement: the numbers and qualifications of crews should be picked allowing for the planned workload on those crews and rational organisation of their work. This requirement is necessary because the composition of a crew depends on the set of jobs it is assigned and the length of work on the number of units and the degree to which the jobs they do can coincide in time. Therefore, an important task is to develop a method for finding optimum performance indicators for assessing a crew. The following researchers contributed greatly to identifying and solving tasks in design of organizational construction processes:

In works [4,7] studied models of efficiency potential of organizational and process-related solutions for a construction project expressed by various factors, which helps take into consideration the impact of organizational and process-related solutions and management decisions when implementing the construction design. In works [8-11] suggested a new approach to determining standards for residential construction timelines. He expands on principles of developing an operational program and organizational and process-related models with reference to measures required to be taken for implementation thereof. In work [12-14] suggests an approach to solving an optimization problem of allocating resources when planning construction and installation. Workforce (crews) is viewed as a resource here, since their number and workload determine one of the most important planning parameters - timelines. In their paper Min Liu and Glenn Ballard [15] state that productivity is not improved by completing as many tasks as possible regardless of the calendar plan, nor from increasing work load, work output or the number of work hours expended. Productivity does improve when work flow is made more predictable, thus enabling a better match of available work load with capacity (labor hours).

In their study Laura Florez and Jean C. Cortissoz [16] propose a methodology to quantify the factors that affect productivity in masonry construction considering three factors: compatibility, suitability, and craft. Alireza Ahmadian Fard Fini and Taha H. Rashidi [17] in their paper present a mathematical model for identifying the optimal combination of singleskilled and multiskilled workers with different levels of experience in the crew to minimize the duration of construction projects by accounting for the overlapping effects of multiskilling and skill level.

\section{Methods}

The purpose of this paper is to develop a method for determining optimum technical and economic parameters for a construction crew's performance. 
A method should be considered legitimate which, given the labour intensity of the jobs assigned to a crew and a list of such jobs, makes it possible to determine the time they will take to do depending on the variation of the following factors:

- Crew numbers

- Job synchronization degree

- Job performance sequence

- Number of shifts

- Unit productivity

- Mechanization of labor.

While the minimum headcount of a multitask integrated crew is set according to the unified quotas or to job diagrams, its maximum value is set according to an expert opinion depending on the list of jobs to be done on site. Modeling results in finding the optimum construction timelines, process synchronization degree, and number of workers.

The complexity and multidimensionality of the method thus formed causes the need for developing a model with the use of mathematical (statistical, simulation) modeling with the aid of a computer program. One basic principle behind forming a model is variation assignment of human resources to jobs to find out the target performance of a crew that directly affects the duration of construction. Another principle influencing the target performance of crews is modeling the degree of synchronization of jobs done by crew units. Also, in parallel with the stated principles, there is a need for variation modeling of the sequence of jobs, the shift numbers, and the productivity of units.

\section{Results}

The research findings have resulted in the model that allows for modeling through varying not only the number of workers and synchronization degree, but also such important factors influencing the end result as the number of shifts, job sequence, and labour productivity.

V. Ya. Mishchenko conducted similar research viewing the workforce (crews) as a resource. This paper, however, suggests a deeper study of comprehensive trial modeling of technical processes aimed at the final performance indicators with a simultaneous variance of the following:

- construction jobs' synchronization degrees at the beginning and end;

- construction and installation work performance sequence;

- hidden idle time of crew units for process and other reasons;

- unit productivity.

- the performance of crews

- the integration level of a crew

- the reliability of a crew

Granted invariance of the result, as the model under consideration is formed it is conceivable that all its elements can and must be capable of being rearranged and of changing as the model functions if this is necessary to achieve a high-quality end result $[18,19]$.

Here is an algorithm for finding the optimum time for individual crew units to do jobs.

The following variables are set at the first stage:

- the total number of crew members (W),

- the number of jobs (R),

- the time a job takes to do, in man-hours $t_{i}$,

- the maximum number of workers for job $\mathrm{i}-\mathrm{w}_{\mathrm{max}, \mathrm{i}}$,

- the minimum number of workers for job $\mathrm{i}-\mathrm{w}_{\min , \mathrm{i}}$, 
- the job synchronization degree $-s_{i}$, if $s_{i}=0$, the synchronization degree for a processes -

$-\mathrm{s}_{\mathrm{i}}$, if $\mathrm{s}_{\mathrm{i}}=0$, the compatibility of processes is $1, \mathrm{~s}_{\mathrm{i}} \in[0 ; 1]$

Given the amount of work and having selected methods for doing them, the labour intensity is calculated using the following formula:

$$
\mathrm{Q}_{\mathrm{i}}=\frac{\mathrm{V}_{\mathrm{i}} \text { Norm }}{8}
$$

where $Q_{i}$ is the labour input (man-hours); $V_{i}$ is the amount of work (m2, m3, pieces); Norm is the standard time (man-hours); and 8 is the duration of a working shift (hours). After calculating the labour input necessary for doing a job, the duration of work is calculated using the following known formula:

$$
t_{i}=\frac{Q_{i}}{k\left(w_{\max , i}\right)}
$$

where $\mathrm{Q}$ is the labour input (man-hours); $w_{\max , i}$ - is set according to an expert opinion, but must be a multiple of the number of workers in crew units as set in the normative documents currently effective in the Russian Federation. $\mathrm{k}$ is the number of shifts in 24 hours.

Then the following final indicators are calculated:

Time bias

$$
r_{i}=s_{i+1} / p_{i}
$$

The sum of the offsets for the $\mathrm{i}$ - th process.

$$
d_{i}=1 / p_{i}+\sum_{j=1}^{i-1} r_{j}=1 / p_{i}+\sum_{j=1}^{i-1} s_{j+1} / p_{j}, \text { where } d_{1}=1 / p_{1}
$$

The total duration is calculated by searching for the maximum duration of a job with the bias

$$
\operatorname{Ad}=\max _{i} d_{i}
$$

Average active time

$$
\mathrm{Me}=\sum_{i=1}^{n} t_{i} / \mathrm{Ad}
$$

Thus by changing the number of workers in crew units and the process synchronization degree, we find the optimum total duration of all jobs.

By modeling using different factors, we then assign the algorithm the task of calculating variation results: the average active time of labour, the total duration of jobs [20,21].

Let us look into an example of modeling the performance of nine jobs by a multitask crew of nine units of 16, 20, 26, and 32 people. Productivity will be set 1 for every example; jobs are done in one shift.

Table 1. Input data for connecting nine jobs with incremental increases in the synchronization degree.

\begin{tabular}{|c|c|c|c|c|c|c|c|c|}
\hline $\begin{array}{c}\text { Duratio } \\
\text { n of } \\
\text { jobs }\end{array}$ & $\begin{array}{c}\text { Labour } \\
\text { intensity }\end{array}$ & $\begin{array}{c}\text { Max. } \\
\text { worker } \\
\text { numbers } \\
\text { (expert } \\
\text { opinion) }\end{array}$ & $\begin{array}{c}\text { Min. worker } \\
\text { numbers } \\
\text { (R.F. } \\
\text { Normative } \\
\text { documents) }\end{array}$ & $\begin{array}{c}\text { What } \\
\text { job is } \\
\text { synchr } \\
\text { onized }\end{array}$ & $\begin{array}{c}\text { Synchr } \\
\text { onizati } \\
\text { on } \\
\text { degree }\end{array}$ & $\begin{array}{c}\text { Sequen } \\
\text { ce }\end{array}$ & $\begin{array}{c}\text { Produc } \\
\text { tivity }\end{array}$ & $\begin{array}{c}\text { Number } \\
\text { of shifts }\end{array}$ \\
\hline 1.6 & 6.3 & - & 4 & - & - & 1 & 1 & 1 \\
\hline 18,7 & 18,7 & - & 1 & 1 & 0,1 & 2 & 1 & 1 \\
\hline 36 & 36 & - & 1 & 1 & 0,1 & 3 & 1 & 1 \\
\hline 6,2 & 6,2 & - & 1 & 2 & 0,1 & 4 & 1 & 1 \\
\hline 2,7 & 2,7 & - & 1 & 3 & 0,1 & 5 & 1 & 1 \\
\hline 6,3 & 12,6 & - & 2 & 3 & 0,1 & 6 & 1 & 1 \\
\hline 4,2 & 8,4 & - & 2 & 5 & 0,1 & 7 & 1 & 1 \\
\hline 5,2 & 10,4 & - & 2 & 6 & 0,1 & 8 & 1 & 1 \\
\hline 18,9 & 37,8 & - & 2 & 8 & 0,1 & 9 & 1 & 1 \\
\hline
\end{tabular}


In table 1 show, by varying the number of workers in crew units and the job synchronization degree, the following end results were obtained.

Table 2. Dependence of job duration (from 23 to 95 days) on the number of workers $(16,20)$ and on the synchronization degree (from 0.1 to 1 )

\begin{tabular}{|c|c|c|c|c|c|c|c|c|}
\hline No & $\begin{array}{c}\text { Total } \\
\text { duration }\end{array}$ & $\begin{array}{c}\text { Number } \\
\text { of } \\
\text { workers }\end{array}$ & $\begin{array}{c}\text { Active } \\
\text { time } \\
\text { factor }\end{array}$ & $\begin{array}{c}\text { Synchronization } \\
\text { degree } \\
\text { (C degr.) }\end{array}$ & $\begin{array}{c}\text { Total } \\
\text { duration }\end{array}$ & $\begin{array}{c}\text { Number } \\
\text { of } \\
\text { workers }\end{array}$ & $\begin{array}{c}\text { Active } \\
\text { time } \\
\text { factor }\end{array}$ & $\begin{array}{c}\text { S. } \\
\text { degr }\end{array}$ \\
\hline 1 & 38 & 16 & 2.6 & 0.1 & 23 & 20 & 2.8 & 0.1 \\
\hline 2 & 40 & 16 & 2.5 & 0.2 & 27 & 20 & 2.4 & 0.2 \\
\hline 3 & 42 & 16 & 2.4 & 0.3 & 31 & 20 & 2.1 & 0.3 \\
\hline 4 & 49 & 16 & 2.0 & 0.4 & 35 & 20 & 1.8 & 0.4 \\
\hline 5 & 57 & 16 & 1.8 & 0.5 & 39 & 20 & 1.6 & 0.5 \\
\hline 6 & 64 & 16 & 1.6 & 0.6 & 42 & 20 & 1.5 & 0.6 \\
\hline 7 & 72 & 16 & 1.4 & 0.7 & 46 & 20 & 1.4 & 0.7 \\
\hline 8 & 80 & 16 & 1.3 & 0.8 & 50 & 20 & 1.3 & 0.8 \\
\hline 9 & 87 & 16 & 1.1 & 0.9 & 54 & 20 & 1.2 & 0.9 \\
\hline 10 & 95 & 16 & 1.1 & 1 & 58 & 20 & 1.1 & 1 \\
\hline
\end{tabular}

As Table 2 shows, the shortest total duration of all jobs is 38 days given the maximum job synchronization degree of 0.1 , while the longest total duration is 95 days with no synchronization $(\mathrm{S}$ degr. $=1)$. The shortest total duration of all jobs is 23 days given the maximum job synchronization degree, while the longest total duration is 58 days with no synchronization.

Table 3. Dependence of job duration (from 19 to 53 days) on the number of workers $(26,32)$ and on the synchronization degree (from 0.1 to 1 )

\begin{tabular}{|c|c|c|c|c|c|c|c|c|}
\hline No & $\begin{array}{c}\text { Total } \\
\text { duration }\end{array}$ & $\begin{array}{c}\text { Number of } \\
\text { workers }\end{array}$ & $\begin{array}{c}\text { Active } \\
\text { time } \\
\text { factor }\end{array}$ & $\begin{array}{c}\text { Synchronization } \\
\text { degree (S degr) }\end{array}$ & $\begin{array}{c}\text { Total } \\
\text { duration }\end{array}$ & $\begin{array}{c}\text { Number } \\
\text { of } \\
\text { workers }\end{array}$ & $\begin{array}{c}\text { Active } \\
\text { time } \\
\text { factor }\end{array}$ & $\begin{array}{c}\mathrm{S} . \\
\text { degr }\end{array}$ \\
\hline 1 & 19 & 26 & 2.9 & 0.1 & 19 & 32 & 3.2 & 0.1 \\
\hline 2 & 21 & 26 & 2.7 & 0.2 & 20 & 32 & 2.8 & 0.2 \\
\hline 3 & 25 & 26 & 2.3 & 0.3 & 21 & 32 & 2.4 & 0.3 \\
\hline 4 & 29 & 26 & 2.0 & 0.4 & 25 & 32 & 2.0 & 0.4 \\
\hline 5 & 33 & 26 & 1.7 & 0.5 & 28 & 32 & 1.8 & 0.5 \\
\hline 6 & 37 & 26 & 1.5 & 0.6 & 32 & 32 & 1.6 & 0.6 \\
\hline 7 & 41 & 26 & 1.4 & 0.7 & 36 & 32 & 1.4 & 0.7 \\
\hline 8 & 45 & 26 & 1.3 & 0.8 & 40 & 32 & 1.3 & 0.8 \\
\hline 9 & 49 & 26 & 1.2 & 0.9 & 44 & 32 & 1.1 & 0.9 \\
\hline 10 & 53 & 26 & 1.1 & 1 & 47 & 32 & 1.1 & 1 \\
\hline
\end{tabular}

The shortest total duration of all jobs in Table 3 is 19 days given the maximum job synchronization degree, while the longest total duration is 53 days with no synchronization of jobs. The shortest total duration of all jobs is 19 days given the maximum job synchronization degree. The longest total duration is 47 days with no synchronization of jobs.

Based on the initial data and statistics of tables 1, 2, 3, in Fig. 1 a Diagram showing the time of execution of tasks depending on the degree of synchronization of tasks. 


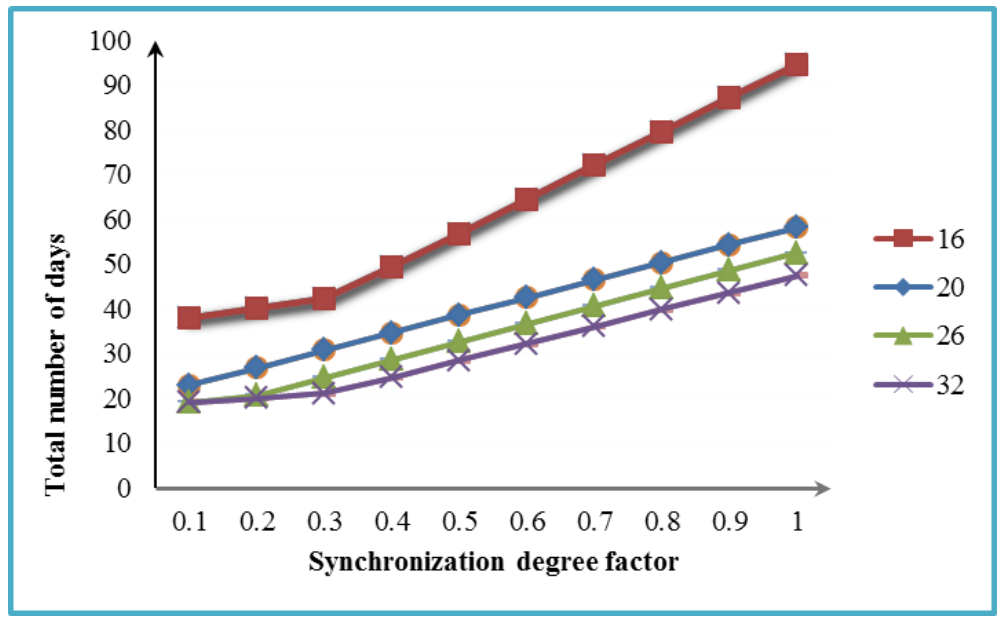

Fig. 1. Diagram of the duration of jobs depending on the job synchronization degree.

\section{Conclusions}

Analysis of the diagram enables drawing the following conclusion: this mathematical model helps determine the optimum construction timelines, job synchronization degree, and number of workers. Thus the optimum total duration in the example under consideration was 19 days given the maximum synchronization degree of 0.1 and the number of workers equaling 26 .

By varying different factors in the model it is possible to find out optimum variants of the duration of a crew's work with an active time factor, which will enable improving the quality of construction work planning.

It should be noted that the model described in this paper enables modeling of processes not only by the number of workers and the degree of overlap, but also by such important factors affecting the final result as labor productivity, shifts, and consistency, the results will be presented in the following publications.

Further scientific research and publications shall focus on developing theoretical recommendations and methodological provisions of organizational and technological nature for the qualitative formation of integrated crews with the aim of increasing their productivity while simultaneously finding the reliability index of the structural unit in which they are included.

\section{References}

1. A.A. Lapidus, I.L. Abramov, Science Bulletin, 4 (2017)

2. I.L. Abramov, T.Y. Poznakhirko, A. Sergeev, MATEC Web of Conferences 86, 04063 (2016)

3. A. Lapidus, I. Abramov, Science and Business, 10 (2017)

4. A.A. Lapidus, Bulletin of Moscow State University of Civil Engineering 1, 175-180 (2014)

5. A.A. Lapidus. A.Yu. Berezhny, Building materials, equipment, technologies of the $21 \mathrm{st}$ century, 12 (2010)

6. E. Chibisova, Journal of International Scientific Publications: Economy \& Business 52, $600(2015)$ 
7. P.P. Oleynik, V.I. Brodsky, Construction Technology and Organization 2(3), 40-43 (2013)

8. P.P. Oleynik, V.I. Brodsky, Construction Technology and Organization 3(4), 35-38 (2013)

9. P.P. Oleynik, Natural and Technical Sciences Journal 10(88), 412-414 (2015)

10. V.Y. Mishchenko, D.I, Yemelyanov, A.A. Tikhonenko, Industrial and Civil Engineering 10, 69-71 (2013)

11. V.Y. Mishchenko, E.P. Gorbaneva, Yoeun Rithy, Fan Noot Lin, Voronezh State University of Architecture and Civil Engineering, Ho Chi Minh City University of Architecture, 28-38 (2016)

12. V. Mishchenko, D.I. Yemelyanov, A.A. Tikhonenko, Voronezh State University Architecture and Civil Engineering, 76-78 (2016)

13. M. Liu, G. Ballard, Proceedings for the 16th Annual Conference of the International Group for Lean Construction, Planning and Control, 657-666 (2008)

14. L. Floreza, J.C. Cortissoz, Procedia Engineering 164, 42 - 48 (2016)

15. A.A. Fard Fini, T.H. Rashidi, Journal of Construction Engineering and Management 142(5), 04015106 (2015)

16. P. De Wilde, D. Coley, Building and Environment 55, 1-7 (2012)

17. A.A. Lapidus. A.N. Makarov, Bulletin of Moscow State University of Civil Engineering 8, 150-160 (2015)

18. S.A. Bolotin, A.Kh. Dadar, I.S. Ptukhina, Engineering and Construction Journal 7, 82$86(2011)$ 